Technology, Pedagogy \& Education

Vol. 16, No. 1, March 2007, pp. $111-126$

P.J. Jefferies, B.C.Stahl and S. McRobb

Pedagogy, Ethics \& Technology in E-learning

\title{
Exploring the relationships between Pedagogy, Ethics \& Technology: Building a framework for strategy development
}

Dr Pat Jefferies ${ }^{\mathrm{a}}$, Dr Bernd Carsten-Stahl ${ }^{\mathrm{b}}$ And Steve McRobb ${ }^{\mathrm{b}}$

${ }^{a}$ University of Bedfordshire, $U K ;{ }^{b}$ De Montfort University, $U K$

\begin{abstract}
The various political and technological drivers that are currently prevalent within many educational institutions increasingly encourage educationalists to experiment with tools that promote e-learning. Many then engage in this activity in the belief that this will help in the development of more autonomous, responsible learners. Strategies for the integration of technology are, however, often less well researched. This paper, therefore, explores the relationship between pedagogy, ethics and technology, as three important constructs for the development of an e-learning strategy. It then proposes a framework that will allow future research to define more clearly how each of these concepts overlap, and to identify the impact that they have on each other. As a consequence, the framework provides insight into the mutual dependencies of pedagogy, ethics and technology, with the aim of avoiding ethical risks in developing e-teaching and e-learning.
\end{abstract}

Keywords: E-learning, information and communication technology, pedagogy, ethics

\section{INTRODUCTION}

For the purposes of this paper e-learning is defined as the use of information and communication technology (ICT) for supporting the educational process. E-learning can, of course, be seen to be increasingly gaining in importance (e.g. Kellner, 1999) as it is now becoming standard in many educational establishments ranging from primary through to higher education. In terms of supporting the learning experience e-learning now finds application in content delivery, in curriculum design and planning, in assessment and recording of

1 An earlier version of this paper was presented at the International Joint conferences on Computer, Information, and System Sciences, and Engineering (CISSE 05), (IEEE) University of Bridgeport, December, 2005. The authors would like to thank the reviewers as well as the audience for helpful comments. 
achievement, and in communication between students and teachers, between students and between teachers. ICT use is, therefore, by now so closely interlinked with the educational process that it is hard to imagine a modern day educational system without it.

Despite the undisputable importance of ICT in education (see Lehtinen, et al, 1999 for a review), there clearly remain a number of issues that are not understood sufficiently (e.g. Lipponen, 2002; Phipps \& Merisotis, 1999). These include the relationships between technological tools available for learning delivery and their links with ethics and pedagogy. The particular significance of these three particular aspects (pedagogy, ethics and technology) was originally uncovered as a consequence of a series of fieldwork studies that were conducted in order to formulate a pedagogically sound foundation to underpin and justify the design of a "mixed mode" context for supporting learning (Jefferies, 2004). Such foundation was based on the social constructivist model of learning (Vygotsky, 1978) and was illustrated within the Pedagogy, Ethics and Technology (PET) framework devised by Jefferies (2004) for developing modules of study where integration of asynchronous computer conferencing (ACC) within face-to-face (F2F) delivery is perceived desirable to support learning and teaching. Our view of the connections and overlaps between the three concepts under discussion in the paper is then further illustrated by the Venn diagram in Fig. 1. There is, of course, much literature on each of the three areas of interest in this paper. There is also a great deal of literature on the relationship between some of them. Pedagogy and e-teaching, for example have frequently been debated and there is some understanding that they refer to each other. Similarly, much has been said about the relationship of technology and ethics. What is largely missing, however, is an attempt to fuse these different strands of debate and come to a coherent understanding of their mutual influences. The main contribution of this paper is thus to close this gap, or at least to start closing it, by providing a conceptual framework that will allow us to see possible relationship between technology, pedagogy, and ethics.

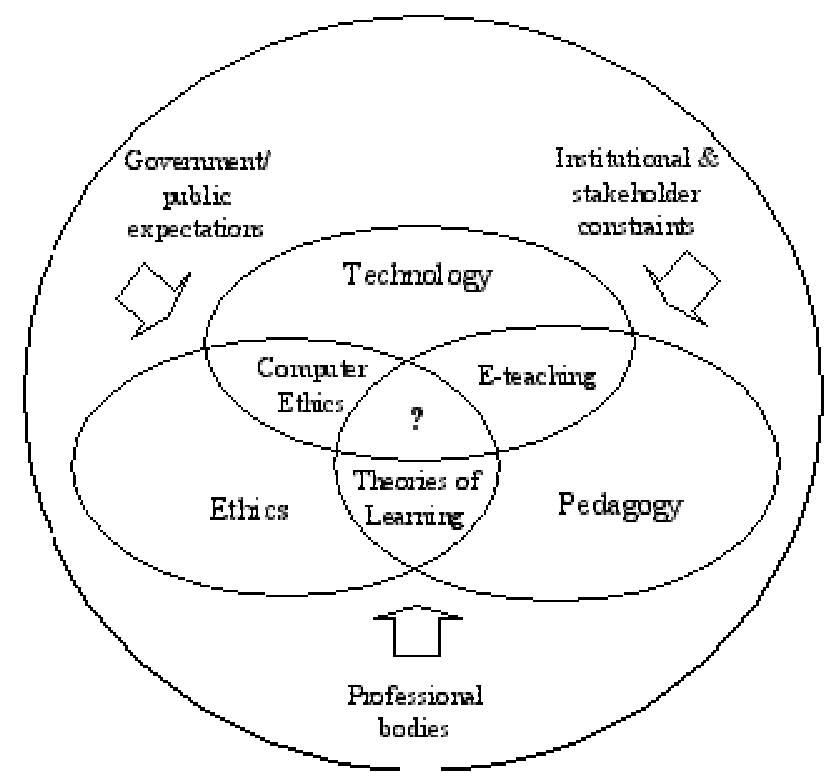

Fig 1. The links between technology, pedagogy and ethics

In order to explore the relationships this paper will first outline the relevance of pedagogy, ethics and technology to e-learning. These particular constituents will then be broken down and discussed with 
reference to the specific areas of interest for the paper. Next, the overlaps between each of the three constituents (pedagogy and ethics, pedagogy and technology, technology and ethics) will be discussed. The three arrows, which represent pressures and constraints on the content of the three circles, raise interesting questions in themselves, but it is not our intention to explore these within this paper. Instead they are left for later research. Finally, the conclusion will explore the centre of the Venn diagram, the overlap between technology, pedagogy, and ethics, in order to prompt the development of an online pedagogy that is cognizant of its ethical implications.

\section{TECHNOLOGY, ETHICS AND PEDAGOGY - THE BUBBLES}

In this section we will briefly introduce our understanding of the main constituents of the diagram depicted in Fig. 1 - technology, ethics and pedagogy - in terms of their relevance to the educational context. The first focus of our research will, therefore, be on pedagogy and the role of education in society. The second task will be to examine the ethical issues that may arise in relation to pedagogy in an e-learning context. Essentially, this means a review of what has been learned from studies in computer ethics over the past several decades, and the use of these concepts to illuminate the issues in e-learning. Of course, other types of ethics have some relevance here - for example, research and educational ethics - but we will focus on computing ethics due to its specific relevance for e-learning. Next, we will identify particular technological tools currently being used to support the learning and teaching process. This will then allow us to consider the assumptions that are contained within them.

\section{Pedagogy: Constructivist versus Positivist Theories}

The literature on pedagogy is large. We have, therefore, focused on two groups of pedagogical theories, which can be broadly characterized as positivist and constructivist. A closer look at prevailing theories of pedagogy reveals that they are not fundamentally pedagogical in nature, but rather result from a prior philosophical stance, which in turn carries specific ontological assumptions about the nature of reality and also about how individual selves (e.g. teachers) interact with others (e.g. students). Positivist approaches, perhaps epitomised in education by the classical behaviourist view of learning as conditioned response (e.g. Skinner, 1938) are based on a realist ontology. This states that the world exists independent of any observer, and that nothing can be treated as real unless it can be measured and described objectively. Constructivist approaches, on the other hand, hold that reality is a construct that cannot be determined independently of the observer. This group of theories cannot be seen as a single, coherent approach, since their antecedents are to be found among widely divergent sources from various disciplines. For example, one of the earlier examples would be the social psychologist G. H. Mead (1934), but such authors as Vygotsky (1978), Wittgenstein (1953), Barthes (1988), and, perhaps most clearly, Berger and Luckman (1966) could be classified under this general heading. What is shared by all the views that we term here 'constructivist' is the belief that, as Mead put it: "We are forced to conclude that consciousness is an emergent from such [social] behaviour; that so far from being a precondition of the social act, the social act is the precondition of [consciousness]" (Mead, 1934).

One implication of positivist realism is that truth can be described as a correspondence between a statement and reality. True statements can be taught, learned, and reproduced. For constructivists, however, truth can only be an agreement between those who are involved in the construction, and teaching should concentrate on the process of being involved in creating useful constructions. E-learning and ICT use in education can, of course, be geared towards either paradigm. Positivist pedagogy necessarily concentrates on the discovery of verifiable objective truths, and thus teaching has the purpose of transmitting known, objective truths to learners. Constructivist pedagogies, on the other hand, concentrate on negotiation and agreement, since it is 
assumed that reality is constituted by the observer and through the act of observation. As Vosniadou (1994) notes, "recent approaches to learning emphasize the active, constructive nature of the knowledge acquisition process wherein the learner is not a passive recipient of information but an active and constructive interpreter of meanings". Thus, the ultimate goal of a constructivist approach is on learning how to construct knowledge appropriate to the situated task - similar to the idea of metacognition, which is the higher order process of reflecting on our own thinking and problem solving processes. This has a powerful problem solving potential. Teaching in this sense cannot be simply the transmission of truth. Rather it is aimed at helping learners to construct their own realities in accordance with social norms.

However, one of the fundamental problems for teachers is to relate the different theories of learning to their teaching strategies as well as to their use of technology. For example, Sfard (1998) argues that there are two metaphors for learning - the "acquisition metaphor" (that which has been acquired by a learner - the product model) and the "participation metaphor" (the learning process itself - the process model). In the first metaphor the act of learning may easily be perceived as being actively engaged in the acquisition of knowledge that, in turn, may be packaged and transmitted (the transmission model). However, in the second metaphor the implied process is a more collaborative, participatory approach, although this seems to neglect the fact that something (i.e. learning) must be acquired. On the other hand, Koschmann (1994) believes that such a dichotomy is too restrictive, and proposes a "transaction metaphor" that encompasses both acquisition and participation.

A further issue then lies in the fact that "learning" may be seen as either an individual or a social activity. For example, Gifford \& Enyedy (1999) argue against both the domain-centred approach to learning - which they state reflects the transmission model of knowledge transfer - as well as learner-centred design - which they suggest is founded on the information processing model of cognition. Rather, they propose an "ActivityCentered-Design" model whose central tenets are that: "Activity is mediated by cultural artifacts, that activity must be analyzed at various levels and that internal activity (thinking) first occurs in the social plane (contextualized activity)" (Gifford \& Enyedy (1999).

Dewey (1901), Vygostsky (1978) and many other researchers have similarly argued that learning begins from a social context. For example, Vygotskian social theory proposes that learning occurs as a result of first participating in activities with others who scaffold the process. Learners then internalize and appropriate skills that then allow them to develop from a novice status to more expert (Hoadley \& Enyedy, 1999; Wertsch, 1985). However, Gifford \& Enyedy (1999) further suggest that mediation changes the nature of the task and that "learning to participate in a cultural practice means moving from partial participation in that practice to full participation". Here again, the actual process of what constitutes "learning" seems to be open to a variety of interpretations although there is clearly a distinction to be made between the conflicting didactic and conversational models of learning as depicted in Fig. 2. 


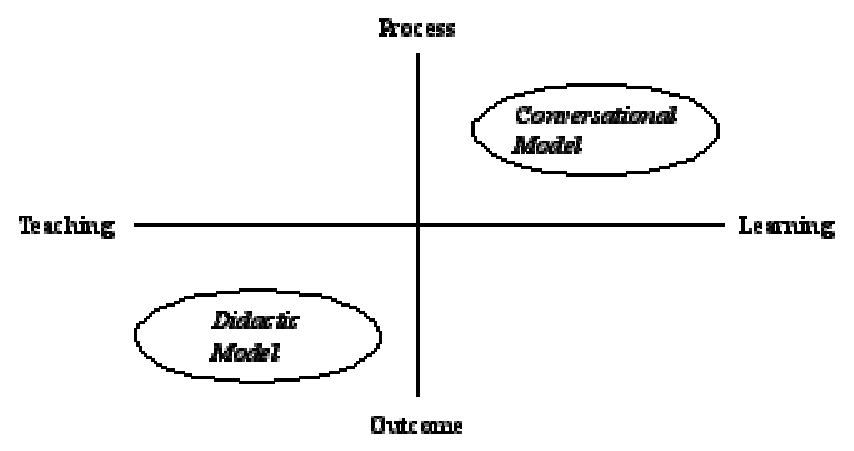

Fig. 2. Conversational versus Didactic model of learning and teaching

\section{Ethics: Computer and Information Ethics}

The field of philosophical ethics may be the largest of the three we have chosen to discuss. Rather than even attempt to mention the most important theories and topics, we will concentrate our discussion, as mentioned above, on the area of computer and information ethics. From its earliest beginnings, arguably in the work of Wiener (1954), this field has developed to become a well established academic sub-discipline. As is true of most academic disciplines, there is no agreement on appropriate approaches or theories. However, there do seem to be a number of recurring topics, which seems to imply an implicit agreement on the subject area of computer ethics. For some of the reference texts of computer and information ethics cf. Bynum \& Rogerson (2004), Johnson (2001), Baird et al. (2000), Spinello \& Tavani (2001), Johnson \& Nissenbaum (1995). Without claiming completeness, we believe that among the most important issues of computer ethics one can find questions of data quality and integrity, access to data and systems including hacking, intellectual property including copyright, privacy and data protection, internet safety, change of social structures through technology, and the impact of ICT on our view of human beings (Mason, 1986). Computer and information ethics have by now come together as a recognised field of intellectual study and have developed many of the characteristics of academic disciplines, including specialist conferences (ETHICOMP, Computer Ethics Philosophical Enquiry [CEPE] or Computers and Philosophy [CAP]) and journals (Ethics and Information Technology, Information, Communication, Ethics \& Society).

For example if programs are of poor quality and do not fulfil their purpose then this can have repercussions for the working of critical systems, can lead to financial losses, and endanger humans. Similarly, high quality data is necessary for ICT to fulfil its purpose (Littlewood \& Stringy, 1995).

However, intellectual property and privacy are probably the most visible and salient issues discussed in computer ethics. While there is no agreement on what exactly the problem is and how it relates to ICT, there is little disagreement that both are important and related to technology. For example, intellectual property increasingly determines the way the economy of the information society works but it is unclear whether traditional concepts can fruitfully be applied to modern technical means (Stahl, 2005). There are questions of the justification of property in general and the transfer of these justifications to the realm of ideas. In particular there is no agreement on whether property rights that were developed with physical artifacts in mind can be applied to intellectual creations. There are several reasons for this. One is the non-exclusionary nature of intellectual property, which means that the ownership of an intellectual artifact such as a text or a piece of music does not necessarily deprive others of the use of the same. Furthermore, there are network effects, which means that shared ideas may actually be more valuable than those that are closely guarded. 
Current political developments in the area of intellectual property seem to increase the scope and protection of intellectual property but there are good ethical arguments that point out that such increased protection goes counter to the original ideas of the protection of intellectual property (Lessig, 1999)

Similarly, there is little agreement on what privacy means or why we value it or how it can be protected. Privacy has been described as an instrumental or an intrinsic value. The intrinsic view means that privacy is something that deserves protection for its own sake. It is thus something like a human right. Others have argued that privacy is important because it serves other purposes such as successful communication or good community relationships. Privacy seems to, at least in some cases, contradict security and in the current political climate security is seen as an important issue. Privacy is thus threatened by states and law enforcement just as much as by private and commercial organisations that collect data on customers and employees. Privacy issues are often discussed in conjunction with the idea of the Panopticon. This all-seeing prison, originally conceived by Jeremy Bentham has risen to fame again due to Michel Foucault's (1975) writings. The Panopticon is a social arrangement which enforces desired behaviour by clandestine observation of the individuals who inhabit it. Technology has given new means of realising this utopian or dystopian idea (Weckert, 2005).

\section{Technology: E-Learning Tools}

Recent surveys have found that a variety of both custom-built and commercially produced virtual learning environments (VLEs), are increasingly being deployed to support education across the HE sector. Each VLE comprises a number of tools that seem to be primarily designed to support content delivery. The tools provided can be used to a) develop repositories that contain a variety of resources (e.g. Powerpoint presentations, Word/PDF documents, Excel/Access files, links to interactive tutorials and other external resources); b) provide assessment through on-line quizzes; and c) provide email communication between tutors and students. There are also tools for supporting discussion forums and synchronous chat; as well as management tools that enable teachers to track student access, to record assignment grades, to manage groups as well as the facility to set up evaluation surveys. It might be perceived that a range of non-routine technology has been developed as a consequence of customized research and development, to support the complex, developing system that is education. (See Fig. 3.)

However, whilst such development is quite likely to have been customized for the educational context, some may view ICT as neutral tools used to achieve the same ends as non-electronic tools previously did. Such an assumption would, of course, be highly questionable as there is a large body of literature which concludes that no technology is value neutral, but rather that all have inbuilt assumptions and ideologies which determine and constrain their possible use (for example, Sachs, 1995; Winner, 1993; Latour, 1996). In this, ICT is no different from any other technology.

For example, within the e-learning context, whilst the ability to provide such things as content or online quizzes within a VLE may provide for autonomy and flexibility of access to learning, it also implies that knowledge can be packaged and transmitted. Thus the assumption reified within the use of these tools is that reality can be objectively defined, packaged and transmitted, and the tools actually support a more traditional, objectivist approach to education. For example, Taylor \& Richards (1987) report that "Bobbitt argued for a scientific approach to planning school curricula by systematic analysis of those human activities which the curriculum was intended to develop. The activities to be focused on were those which made for efficiency in living as a healthy, gainfully employed citizen. Those activities, analyzed in detail, would be the 
intended outcomes of the curriculum". This, in simplistic terms, may be seen to reflect a deterministic view of a 'closed' system in which specific outcomes may be defined for appropriately developed processes to achieve. Theories of education such as that proposed by Bernstein (1977) added weight to deterministic approaches through the identification of what were perceived to be desired, observable behaviours. To a great extent, traditional, positivist approaches to education stemmed from particular beliefs of what learners ought to learn, and these, in turn, were based upon the notion that the goal of learning is to understand reality, which is taken to be objective. For theorists such as Bernstein (1977), achievement of learning was also deemed to be measurable through observable behaviour. Assessment could therefore be framed in simple stimulus-response terms, reflected in the use of online quizzes where a determined truth is presented to students, and they are graded according to their ability to pick the right answer.

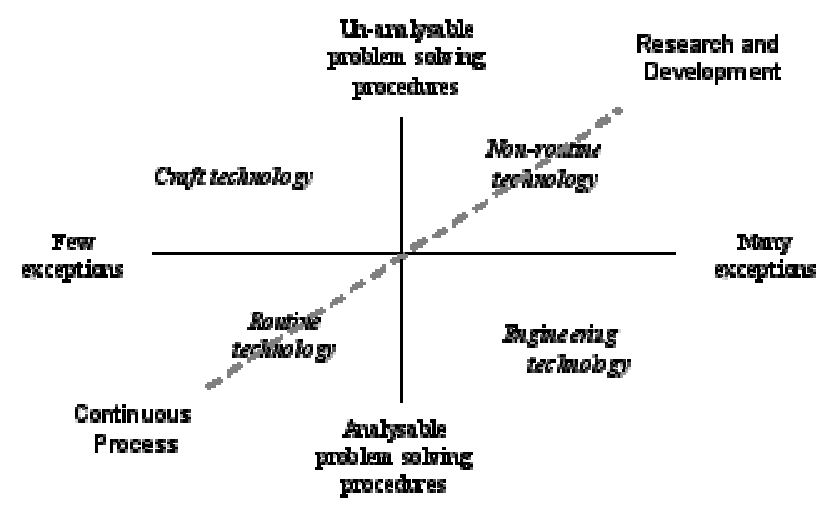

Fig. 3. The Perrow model of technology (Perrow, 1972)

However, the use of such tools can also be seen to reinforce a particular relationship between technology and our view of humans (Wiener, 1954; Weizenbaum, 1976). For example, if we see humans as information processing machines, then failure to process information in the desired way is a failure of the machine, which may require reprogramming or being exchanged. This view may conflict with ethically inspired views of humans.

On the other hand, the use of discussion boards can be seen as supporting a completely different approach, in that the learning to be undertaken is not necessarily gained from acquiring "chunks" of knowledge but instead is constructed through discourse (Jefferies, 2003; Jefferies \& Rogerson, 2003). This wider scope of discourse in learning is further expressed in the work of academics on reflective learning in professionals (Schon, 1983), action learning sets (Beaty, 1997) and cognitive development (Vygostsky, 1978). Thus use of this type of tool can be seen to relate to an underlying philosophy regarding the role of education in general and the teacher in particular and it is suggested that it is these more complex conversational frameworks that are clearly the type of constructs that Perrow (1972) identifies as requiring 'Non-routine technology' when seeking a technological solution.

\section{INTERSECTIONS}

Having established the main content of each of the three aspects of our analysis: pedagogy, ethics and technology, we will now briefly discuss the areas where they overlap. 


\section{Ethics and Technology: Computer Ethics and E-teaching Tools}

To start this section, we should state that there is a close link between ethics and education in general. Scrimshaw, (1983) for example, identifies several different educational ideologies - Progressivism (meeting individuals needs and aspirations), Instrumentalism (meeting requirements of the socio-economic order), Reconstructionism (moving society in desired ways), Classical humanism (transmission of cultural heritage), and Liberal humanism (creation of a vision of common educational experience). Independent of which school of thought one wants to follow, one can easily make a strong claim about a link between ethics and education. Education is usually seen as an ethical good that allows the student to develop independence, autonomy and the skills to provide for his or her livelihood (Stahl, 2004). We have stressed several times already that e-teaching tools are not value neutral but their use has consequences which have ethical importance. To return to the list of issues raised in our earlier discussion of technology, we can look at the impact that e-teaching tools have on privacy, intellectual property, data quality, social structures, and the view of humans.

In all cases, it is relatively simple to observe or imagine relationships between computer ethics and eteaching tools. If we take the example of VLEs then we can identify aspects of these that are related to ethics. Privacy and data protection, for example may be affected when data on students or staff is collected that previously was not available. As noted earlier, many of the standard commercially available VLEs, such as Blackboard, allow teachers to check the usage of the site by their students. Teachers thus have information as to how often students have accessed which part of the VLE, at what time of the day etc. This can affect the teacher's evaluation of the student and this may have grave consequences for the student. Similarly, a VLE may raise issues of intellectual property. If teaching material is put online and students are able to download it, then they may use and modify it electronically, thus allowing them an easy route to infringement of copyright. Data quality is also important because the quality of the learning experience will be affected by the quality of the data provided. This was certainly true before VLEs but it becomes more salient due to the increasing reliance on quantitative data in an information technology environment.

Another ethical issue regarding ICT is its impact on social relations, be they between nations, within societies or organizations. One part of this is the question of digital divides but it also extends to political and organizational power relationships. These tend to produce social consequences, that in turn have ethical importance. For example, some tools, such as multiple choice tests, are very reliable, easy to use and therefore favoured by teachers. What is noticed less often is that they also imply a certain relationship between teachers and learners, namely that of the 'sage on the stage' who tells students the truth rather than 'guide on the side' who encourages students to fulfil their own goals. In effect, this translates into a very strong centralized position of the teacher whereas other teaching tools, such as online chats, voting tools etc, imply different power relationships. Such organizational relationships are central to the way we perceive humans and the resulting ethical questions. Are students machines of data digestion that need to reproduce the truth as taught and then function in their economic role or are they autonomous persons whose purpose in life is to flourish? Such questions of course go beyond the use of technology in teaching, but they are affected by our use of technology.

Another example was recently directly observed by one of the authors. During an external quality review at his faculty, several assessors were temporarily 'enrolled' as guests on a number of module VLE sites. This was conceived as a way of providing access to documents such as module outlines, assessment specifications and so forth, and there was no prior consultation with module tutors. It emerged that no-one in authority had 
considered that this also allowed access to email communications, online discussions and virtual classrooms - areas where teachers and students might reasonably expect their discussions to be private, and where normally no inspector or manager would intrude without prior arrangement and due warning. While there is no evidence of a hidden agenda in this particular case, it clearly raises questions about the sorts of information that could be collected and the uses to which they could be put, thus illustrating Feenberg's (1999) argument that control of technology is tantamount to a form of legislation.

\section{Technology and Pedagogy: E-teaching Tools and Pedagogical Theories}

As noted earlier the use of a number of VLE tools (email, tutorials, quizzes, Web pages, and Powerpoint) can all be clearly related to a positivist pedagogy in that the learners are provided with tools that will scaffold and mediate their learning experience through giving them access to what has been selected and designed by the teacher.

Use of the discussion boards however, has been shown to not only have the potential for supporting the participatory/transaction models of learning but can also facilitate a more androgogic (Knowles, 1970) social constructivist pedagogy. There is, for example, a great deal of empirical research that reports the benefits and potential of networked learning (see Lehtinen, Hakkarainen, Lipponen, Rahikainen and Muukkonen, 1999 for a review) and, in particular, the positive effects of social interaction during learning (e.g. Crook, 1999; Dillenbourg, 1999). Additionally, other research has found that collaboration amongst students has been shown to stimulate activity, make learning more realistic and to stimulate motivation (e.g. Harasim, 2000; Veerman, and Veldhuis-Diermanse, 2001). Furthermore, Bligh (1998) concluded that discussion methods are more effective than didactic methods (e.g. lectures) for stimulating thought, for personal and social adjustment, and for changes of attitude, and were hardly worse than lectures for effectively transmitting information.

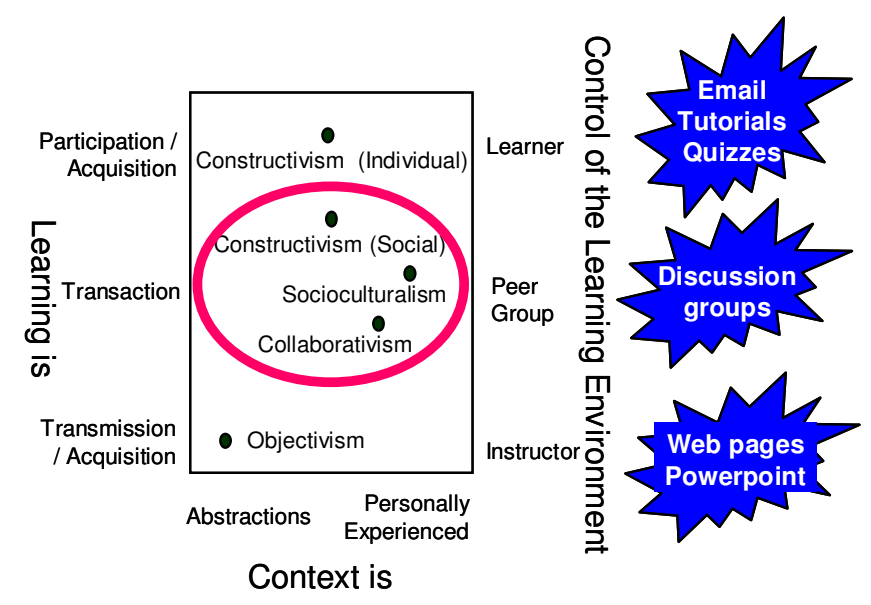

Fig. 4. Dimensions of learning mapped to technological tools

Thus, taking the three models of learning that Koschmann (1994) proposes and applying this to a modified version of the Leidner and Jarvenpaa (1995) framework (Fig. 4) it can easily be illustrated that VLEs can support the various pedagogical models. However, whilst the uptake of VLEs has shown a dramatic increase by institutions there is still a tendency for them to be largely used for course administration purposes as well as to support the more traditional student-tutor relationships. For example "the MLE landscape report survey in 2003, which received returns from 358 institutions across both HE and FE, 
reports a very high prevalence of VLE usage in all types of institutions surveyed. $85 \%$ of FE colleges, $84 \%$ of pre-1992 universities and 97\% of post-1992 universities report using one or more VLEs in their institution (Britain \& Liber , 2003). However, "despite high VLE uptake by institutions, uptake by learning and teaching staff remains relatively localised, and use by students is often ad-hoc and optional" (Britain \& Liber , 2003). "This suggests that many institutions are still at a stage of tentative exploration of the use of elearning rather than mainstream adoption" (Britain \& Liber , 2003). This, in turn, would suggest that the training of modern day teachers now needs to include the development of new approaches to course design if VLEs are to become properly integrated into the education system. There remains, therefore, a great deal more work to be done both to develop the technological tools that are available as well as in ensuring that an e-learning/blended learning pedagogy is developed.

\section{Pedagogy and Ethics: Pedagogical Theories and Computer Ethics}

In distinguishing earlier between constructivist and positivist pedagogical theories, we have already identified that there may be a link between computer ethics and pedagogy.

Following our earlier characterization of pedagogical theories, certain pedagogical theories also correspond with certain ethical approaches because they are based on similar ontologies and general philosophical worldviews. In the positivist / realist world, one can presume that there are valid ethical theories and that these will lead to determined morally correct actions. The task of computer ethics will thus be to find out what the moral problems are, how they should be evaluated, and to help individuals and collectives do what is ethically desirable. This reasoning is represented by prescriptive approaches to computer ethics, which concentrate on professional duties of the individual (Gotterbarn, 2004). Van den Hoeven (1997) calls this approach the "engineering model" of ethics, because it assumes that there is one correct solution to an ethical problem.

Ethicists closer to the constructivist understanding of reality would be careful about the possibility of such a determinist approach to ethics. If reality is a social construction, then there can be no objective ways to determine the ethicality of an action and thus no general moral rules that are binding for everybody under all circumstances. For the constructivist, addressing ethical issues of ICT must therefore involve a process of agreement on the definition and understanding of the problem and a collective attempt to define an adequate response. Constructivists will therefore be more participative and discourse oriented, and will try to involve all stakeholders in a solution (cf. Rogerson, 2004).

Examples of the link between pedagogical views and computer ethics are easily found. They can be drawn from the general canon of computer ethics. Privacy and surveillance can be seen as primary examples. The use of modern virtual learning environments (VLEs) such as Blackboard allows teachers a formerly unimaginable access to data about students and their behaviour. VLEs display data about student access to the learning material in a very detailed manner - one can check dates and times of access and the number of clicks on the website. This information can be used to force students to access material in situations where teachers before could only hope that students would do so. There are possible links between this and pedagogical theories. An educational positivist / realist who believes that true statements can be transmitted for the purpose of learning may be tempted to use such surveillance mechanism to assess students efforts and draw conclusions about their educational attainment. A constructivist who wishes to use the same features of technology might look at the students' use of communicative features of the technology such as blogs or 
A further example may be the relationship of power, created by technology, and pedagogy. ICT in general has always been perceived as a means of power exertion. VLEs can again be seen as an example. Not only can the instructor carry out surveillance upon the students, he/she can also limit or open access to learning material in a much more focused way than before. This can be linked in with issues of intellectual property where VLEs can be used to enforce IP rules and regulations. Interestingly, they can also be used for the opposite where a lecturer may feel freer to post copyright material online because the closed nature of the system makes it less likely that the copyright holder will notice the transgression. Control features of technology can also be linked to non-academic circumstances. A student who fails to pay his/her tuition fee, for example, may be de-enrolled and automatically excluded from access to the VLE. In a learning environment that relies heavily on access to the system, the technologically enabled de-enrolment of a student may have more direct and drastic consequences for student participation than was possible before. Control features of teaching technology can also link directly to pedagogical views. A directly controllable environment with the corresponding power of the instructor may be appealing to a positivist who will find it easier to disseminate her knowledge whereas it is likely to be less appealing to the constructivist whose view of the process of instruction is a different one. It can also have conceivable consequences for methods of assessment.

While this characterization is more black and white than actual positions tend to be, it does indicate that there is a link and an overlap between certain positions in computer ethics and specific pedagogical theories.

\section{CONCLUSION: THE CENTRE}

The aim of the paper was to develop a framework that would allow us to locate areas of interest in the overlap of ethics, technology, and pedagogy. Based on the assumption that e-teaching and e-learning are ethically relevant uses of technology in education, we tried to identify areas of overlap and commonalities which might help us concentrate our research efforts with the aim of facilitating a better use of ICT in education. Our discussion of these issues has shown that there are fundamental philosophical assumptions which we need to be aware of in order to deal with the issues. One such central assumption stems from ontology. Depending on whether we follow a realist / positivist view of the world as external to the observer or a constructivist view, we will have a different understanding of technology as well as ethics and pedagogy. A similar fundamental issue is that of the nature of humans and their role in society. Philosophical anthropology is closely linked to ethics and education but it also has links with technology.

Currently there seems to be little interest in the exploration of the intersection of these areas. E-teaching and e-learning are timely issues of interest but the majority of research in the area is narrow in its scope. This is of course legitimate and the consequences of the use of a certain technology or the relationship of a particular pedagogy with technology are questions of interest. What appears to be lacking, however, is a good overview of the relationships of the different issues involved. In this paper we have made a first step to address this shortcoming of the debate. We are sure that there are many more views and theoretical approaches worth exploring. It is therefore not the purpose of the paper to present a comprehensive framework. Instead, we see the framework developed here as a starting point that can and should be added to. We are also aware of the fact it is unlikely that there will ever be a general agreement on the matters presented here. Our own ontological, anthropological and ethical beliefs are sure to have coloured the narrative. It is nevertheless important to discuss the issues raised here. One reason for this is that there are instrumental and functional objectives that can be linked to it. If a given technology is not compatible with the underlying pedagogy or if the pedagogy conflicts with ethical ideas, then it is likely that the purpose of the use of technology, namely to 
educate, is in danger of not being fulfilled. Closer attention to these issues can thus arguably lead to higher success rates. This is an argument that should appeal even to those readers whose philosophical assumptions differ radically from our own.

A second and more important reason is that the above considerations go to the heart of what education is about. Education and the institutions delivering it have a high degree of legitimacy, which is partly caused by the perceived moral advantages they offer (Stahl, 2004). Developments that lead to doubts about the moral acceptability of education have the potential to undermine its legitimacy and can therefore threaten the way we perceive education. It is therefore in the interests of everybody involved to consider the relationship of ethics and education and, as we have argued here, this includes reflecting on the conceptual links between technology, pedagogy and ethics.

\section{REFERENCES}

Baird, R.M., Ramsower, R. \& Rosenbaum, S.E. (eds.) (2000) "Cyberethics - Social and Moral Issues in the Computer Age" New York: Prometheus Books

Barthes, R. (1988) "The Semiotic Challenge". New York: Hill and Wang

Beaty, L. (1997) "Developing Your Teaching Through Reflective Practice”, SEDA Special Publications

Berger, P. L. and Luckmann, T. (1966) "The Social Construction of Reality: a treatise in the sociology of knowledge". Garden City, NY: Doubleday

Bernstein, B. (1977) "Class, Codes and Control", Volume 3, Towards a theory of educational transmissions. London: Routledge \& Kegan Paul

Bligh, D. (1986), "Teach Thinking by Discussion”, Society for Research into Higher Education, NFER Nelson

Britain, S \& Liber, O (2003) "A Framework for the Pedagogical Evaluation of Virtual Learning Environments", JISC. Available at: http://www.jisc.ac.uk/uploaded documents/VLE\%20Full\%20Report\%2006.doc (accessed 16 October, 2006)

Bynum, T.W. \& Rogerson, Si. (2004) (eds.) "Computer Ethics and Professional Responsibility" Oxford et al.: Blackwell Publishing

Crook, C., (1999) "Computers in the community of classrooms". In K. Littleton and P. Light (Eds) Learning with computers. Analysing productive interaction. London and New York: Routledge, pp. $102-117$

Dewey, J. (1901) "Psychology and Social Practice". Chicago, IL: University of Chicago Press.

Dillenbourg, P. (1999) "Introduction: What do you mean by 'collaborative learning'?" In P. Dillenbourg (Ed.), Collaborative Learning: Cognitive and computational approaches (pp. 1-19) Amsterdam: Pergamon, Elsevier Science. 
Feenberg, A. (1999) "Questioning Technology". London: Routledge.

Foucault, M.(1975) "Surveiller et punir: Naissance de la prison" Paris: Gallimard

Gifford, B.R. and Enyedy, N.D. (1999) "Activity Centred Design: Towards a Theoretical Framework for CSCL". In Proceedings of the Computer Support for Collaborative Learning (CSCL) 1999 Conference, C. Hoadley and J. Roschelle (Eds) Dec. 12 - 15, Stanford University, Palo Alto, California, Mahwah, NJ:Lawrence Erlbaum Associates. Available at: http://www.ciltkn.org/cscl99/A22/A22.HTM (accessed 5 March 2001)

Gotterbarn, D. (2004) "Informatics and professional responsibility," in Bynum, T. W. \& Rogerson, S., Eds. Computer Ethics and Professional Responsibility, Oxford: Blackwell Publishing, pp.107 $-118$.

Harasim, L. (2000) "Shift Happens: Online Collaborative Learning as a New Paradigm in Education". Keynote Speaker at Fusion 2000. Glasgow, Scotland.

Hoadley, C.M. and Enyedy, N. (1999) "Between Information and Communication: Middle Spaces in Computer Media for Learning". In Proceedings of the Computer Support for Collaborative Learning (CSCL) 1999 Conference, C. Hoadley and J. Roschelle (Eds) Dec. 12 - 15, Stanford University, Palo Alto, California, Mahwah, NJ:Lawrence Erlbaum Associates.

Jefferies, P. (2003) "ICT in Supporting Collaborative Learning: Pedagogy and Practice", Journal of Educational Media, Vol. 28, No. 1, March 2003

Jefferies, P. \& Rogerson, S., (2003) "Using Asynchronous Computer Conferencing to support the teaching of Computing and Ethics: a Case Study" published in the fifth volume of Annals of Cases on Information Technology (ACIT), Idea Group Publishing, USA, 2003

Jefferies, P. (2004) "Aspects of Technology mediated interaction and its impact on Higher Education", PhD Thesis, De Montfort University

Johnson, D.G. (2001) "Computer Ethics" 3rd edition, Upper Saddle River, New Jersey: Prentice Hall

Johnson, D.G. \& Nissenbaum, H.(eds.) (1995) "Computers, Ethics \& Social Values" Upper Saddle River: Prentice Hall

Kellner, D., (1999) "New Technologies: Technocities and the Prospects for Democratization" in Technocities, eds Downey, J and McGuigan, J, Sage Publications

Knowles, M.S. (1970) “The Modern Practice of Adult Education: Androgogy vs. Pedagogy”. New York: Association Press.

Koschmann, T., (1994) "Toward a theory of computer support for collaborative learning. Journal of the learning sciences, 3, 219-225

Latour, B. (1996) "Where are the missing masses? The sociology of a few mundane artefacts," in Bijker, W. and Law, J., Eds., Shaping Technology / Building Society, MIT Press, pp. 225 - 228. 
Lehtinen, E., Hakkarainen, K., Lipponen, L., Rahikainen, M., and Muukkonen, H., (1999)

"Computer supported collaborative learning: A review of research and development" (The

J.H.G.I.Giesderbs Reports on Education, 10). Netherlands:University of Nijmegen, Department of Educational Sciences.

Leidner, E.D. and Jarvenpaa, S.L. (1995) "The Use of IT to enhance Management School Education: a theoretical view", MIS Quarterly 19, (3) pp 265-291

Lessig, L.(1999) "Code and Other Laws of Cyberspace" New York: Basic Books

Lind, G., (2001) "Introducing the Moral Judgement Test: Measurement of Moral Judgement Competence and Moral Attitudes for Research and Evaluation. Available at: http://www.unikconstanz.de/ag-moral/mut/mjt-intro-engl.htm. (accessed 23 August, 2001)

Lipponen, L., (2002) "Exploring foundations for computer-supported collaborative learning". In T.Koschmann, R.Hall and N. Miyake (Eds), CSCL2: Carrying forward the conversation. Mahwah, NJ: Lawrence Erlbaum Associates. Proceedings of the Computer-supported Collaborative Learning 2002 Conference (pp. 72-81). Hillsdale, NJ: Erlbaum. Available at: http://newmedia.colorado.edu/cscl/31.html (accessed 2 May, 2002)

Littlewood, B. \& Stringy, L. (1995): The Risks of Software. In: Johnson, Deborah G. / Nissenbaum, Helen (eds.) (1995): Computers, Ethics \& Social Values. Upper Saddle River: Prentice Hall 432 437

Mason, R. O. (1986): Four Ethical Issues of the Information Age. In: MIS Quarterly 10: 5 - 12

Orlikowski, W. J. \& Baroudi J. J. (1991): Studying Information Technology in Organizations: Research Approaches and Assumptions. In: Information Systems Research (2:1): 1 - 28

Perrow, C. (1972) "Complex Organisations", Scott-Forsman

Phipps, R., \& Merisotis, J. (1999) "What's the difference?: A review of contemporary research on the effectiveness of distance learning in higher education". Washington, DC: The Institute for Higher Education Policy. (Washington, DC, The Institute for Higher Education Policy). Available at: http://www.ihep.com/Pubs/PDF/Difference.pdf (accessed 28 October, 2003)

Rogerson, S. (2004): The Ethics of Software Development Project Management. In: Bynum, Terrel W. \& Rogerson, Simon (eds.) (2004): Computer Ethics and Professional Responsibility. Oxford et al.: Blackwell Publishing: $119-128$

Sachs, P. (1995) "Transforming work: collaboration, learning and design," in: Communications of the $\operatorname{ACM}(38: 9)$, pp. $36-44$.

Schon, D. (1983) "The Reflective Practitioner", London, Temple Smith

Scrimshaw, P. (1983) "Educational Ideologies", Unit 2, E 204, Purpose and Planning in the Curriculum. Milton Keynes: Open University Press

Sfard, A., (1998) "On two metaphors for learning and the dangers of choosing just one". Educational Researcher, 27(2), 4-13 
Skinner, B. F. (1938) "The Behavior of Organisms". New York: Appleton.

Spinello, R.A. \& Tavani, H.T. (eds.) (2001) "Readings in Cyberethics". Sudbury, Massachusetts et al.: Jones and Bartlett

Stahl, B. C. (2005): "The Impact of Open Source Development on the Social Construction of Intellectual Property" In Koch, Stefan (ed.): Free / Open Source Software Development. Idea Group Publishing, Hershey PA: 259 - 272

Stahl, B. C. (2004): "E-Teaching - the Economic Threat to the Ethical Legitimacy of Education?" In: Journal of Information Systems Education (15:2), 155 - 162

Stahl, B. C., Prior, M., Wilford, S. \& Collins, D., (2005): "Electronic Monitoring in the Workplace: If People Don't Care, then What is the Relevance?" In: Weckert, John (ed.): Electronic Monitoring in the Workplace: Controversies and Solutions. Idea-Group Publishing, Hershey PA: 50 - 78

Taylor, P.H. \& Richards, C.M. (1987) "An Introduction to Curriculum Studies", Nfer-Nelson

van den Hoeven, J. (1997) "Computer ethics and moral methodology," in Metaphilosophy (28:3), pp. $234-248$.

Veerman, A. and Veldhuis-Diermanse, E. (2001) "Collaborative learning through computermediated communication in academic education" in the Proceedings Euro CSCL 2001, Maastricht, 22-24 March , 2001. Available at: http://www.mmi.unimaas.nl/eurocscl/Papers/166.doc, (accessed 5 March, 2001)

Vosniadou, S. (1994) "From cognitive theory to educational technology", in Vosniadou, S., De Corte, E. Mandl, H. Technology-Based Learning Environments, Berlin, Springer-Verlag, pp. 1118

Vygotsky, L.S., (1978) "Mind in Society: The Development of Higher Psychological Processes". Cambridge, MA: Harvard University Press

Weckert, J.(ed.) (2005) "Electronic Monitoring in the Workplace: Controversies and Solutions" Hershey, PA: Idea Group Publishing

Weizenbaum, J. (1976) "Computer Power and Human Reason". San Francisco: W. H. Freeman and Company

Wertsch, J. (1985) "Vygotsky and the Social Formation of Mind". Cambridge, MA: Harvard University Press

Wiener, N. (1954) "The Human Use of Human Beings - Cybernetics and Society". Garden City, New York: Doubleday Anchor Books

Winner, L. (1993) "Upon opening the black box and finding it empty: social constructivism and the philosophy of technology," in Science, Technology and Human Values (18), pp. $362-378$.

Wittgenstein, L. (1953) "Philosophical Investigations". Oxford: Blackwell. 